This item was submitted to Loughborough's Research Repository by the author.

Items in Figshare are protected by copyright, with all rights reserved, unless otherwise indicated.

\title{
Frequency reconfigurable RF circuits using photoconducting switches
}

PLEASE CITE THE PUBLISHED VERSION

http://onlinelibrary.wiley.com/journal/10.1002/(ISSN)1099-047X

\section{PUBLISHER}

(c) Wiley Periodicals, Inc.

\section{VERSION}

SMUR (Submitted Manuscript Under Review)

LICENCE

CC BY-NC-ND 4.0

\section{REPOSITORY RECORD}

Draskovic, D., C.J. Panagamuwa, J.C. Vardaxoglou, and D. Budimir. 2019. "Frequency Reconfigurable RF Circuits Using Photoconducting Switches". figshare. https://hdl.handle.net/2134/5808. 
This item was submitted to Loughborough's Institutional Repository (https://dspace.lboro.ac.uk/) by the author and is made available under the following Creative Commons Licence conditions.

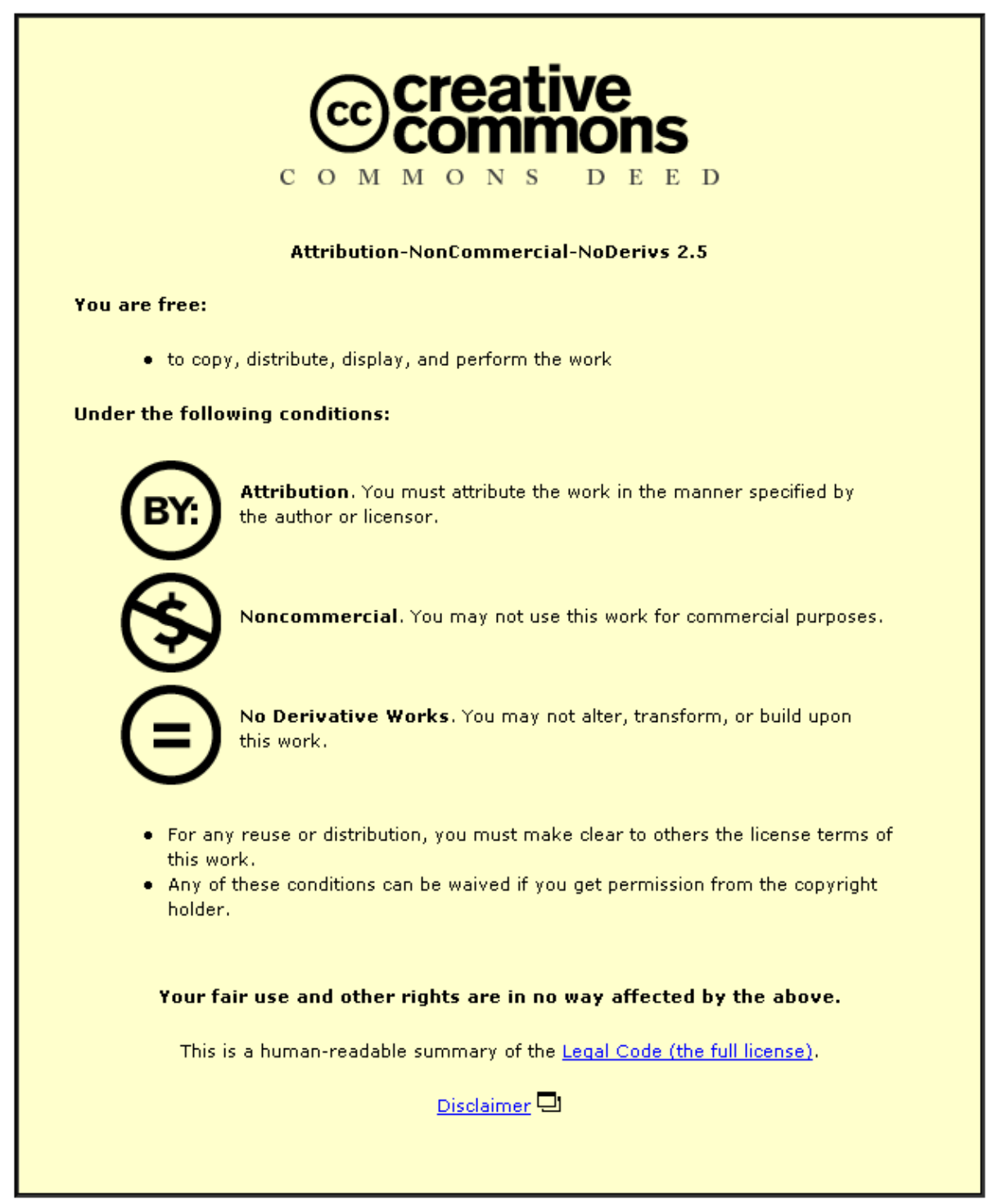

For the full text of this licence, please go to: http://creativecommons.org/licenses/by-nc-nd/2.5/ 


\title{
Frequency Reconfigurable RF Circuits Using Photoconducting Switches
}

\author{
D. Draskovic ${ }^{\# 1}$, C. Panagamuwa ${ }^{* 2}$, J. C. Vardaxoglou ${ }^{* 3}$ and D. Budimir ${ }^{\# 4}$ \\ ${ }^{\#}$ Wireless Communications Research Group \\ Department of Electronic, Communication and Software Engineering \\ University of Westminster \\ London W1W 6UW, United Kingdom \\ d.budimir@westminster.ac.uk
}

*Wireless Communications Research Group, Loughborough University, Ashby Road, Loughborough, UK

\begin{abstract}
Designs for a frequency switchable dual-band branch-line coupler and a reconfigurable S-band power amplifier input matching network with photoconducting switches are presented. Frequency switching is achieved by increasing the power of the laser applied to the highly resistive silicon wafer and changing the properties of silicon under optical illumination. The advantages of this approach are high-speed switching, electromagnetic transparency (no interference) and thermal and electrical isolation between the device and the control circuit. A branch-line coupler frequency shift of 35\% and $10 \%$ has been achieved from all switches off to all switches on in lower (900 MHz) and upper (1800 $\mathrm{MHz}$ ) frequency bands, respectively. Frequency switchable class AB power amplifier with silicon switch in the input matching circuit has obtained the frequency tuning range of 2.5-3.5 GHz with no significant loss in efficiency and linearity.
\end{abstract}

Index Term-frequency switchable, branch-line coupler, power amplifier, silicon switch 


\section{Introduction}

Novel components for future wireless communications systems will have to meet the demands of Cognitive Radio and Software Defined Radio (SDR). The common directions in design of these novel components are component miniaturisation, design of components with enhanced bandwidth, design of multiband components and design of tunable components. Over the past few years, branch-line coupler designs with bandwidth enhancement and size-reduction have been gaining favor. Recently, the interest in tunable microwave components, such as couplers, baluns, phaseshifters, filters has arisen. Tuning techniques include varactor/pin diodes, RF MEMS, ferroelectrics and optical tuning. The use of pin and varactor diodes has many disadvantages such as high loss, high power consumption, unacceptable SNR and distortion of the incident signals. RF MEMS provide a better solution in building tunable passives, which are necessary for multiband systems. These passives are small, with low insertion loss, high $\mathrm{Q}$ and low power consumption, they introduce less signal distortion, but the fastest tuning speeds are around a microsecond. Ferroelectric materials have fast tuning speeds ( picoseconds). They are easily tuned by voltage only. Their main disadvantage is high level of dielectric loss. The advantages of the optically controlled microwave devices include high isolation between the controlling optical beam and the controlled microwave signal, short response time, high-power handling capacity, immunity to electromagnetic interference and low cost. Optically controlled antennas [1], filters [2], resonators [3], phase-shifters [4], have been demonstrated recently.

The aim of this work is to produce frequency switchable RF circuits for microwave applications. The branch-line coupler device presented in this paper was produced by modifying a dual-band branch-line coupler and adding four silicon switches. The frequency switchable power amplifier was produced by inserting silicon switch into the input matching network, while the output matching network was not changed. 
International Journal of RF \& Microwave CAE

\section{Photoconductive Devices}

The photoconducting properties are used in order to optically switch or tune microwave and mmwave structures. The semiconductor conductivity changes when exposed to light of a certain wavelength and flux density. Microwave switches with silicon $(\mathrm{Si})$ as a photoconductor have the ability to be integrated into most of today's communication systems (smart antennas, tunable metamaterials, novel filters).

In 1975 the first silicon photoconducting switch was demonstrated by Auston [6]. The first switch operated by illuminated gap was reported in 1989 by Anderson et al. [7]. They used GaAlAs/GaAs laser at $805 \mathrm{~nm}$. Horii and Tsutsumi [8] did the same experiment with interdigital gap and got superior characteristics over the single straight gap. The first lumped element equivalent circuit of the gap on silicon substrate was proposed by Gevorgian [9]. The equivalent circuit is an important tool for simulation and optimisation of the performance of the switch. A frequency tunable antenna was designed by Panagamuwa et al. [1] using a pair of optically operated microswitches. The illumination from a laser diode was focused on two Si switches placed onto the gaps in the dipole arms. The center frequency of the antenna was shifted by $40 \%$ when both switches were activated.

The photoconducting property of Silicon can be used to optically control Electromagnetic Band Gap (EBG) based structures. EBG structures have unique frequency selective properties. In 1987 Yablonovitch [10] introduced photonic crystals, and attracted interest due to the ability of these structures to be engineered for different applications. EBG and PBG (Photonic Band Gap) materials have the unique property that within certain bands of frequency, electromagnetic waves cannot propagate through the structure. The term PBG is not widely accepted, and it has been used to describe microwave phenomena which occur in EBG structures. The EBG structures have found many applications within the fields of optical and microwave communications. The applications 
International Journal of RF \& Microwave CAE

include microstrip lines based filters and substrates for printed antenna structures. Vardaxoglou et al. demonstrated frequency switchable filter [2], optically operated phase shifter and optically controlled microstrip patch antenna. A frequency switchable microstrip filter for microwave applications was realised by modifying a single pole parallel-coupled line filter, and the wave propagation in the filter is controlled by varying the structural parameters. Silicon switches were employed to alter the dimensions of the filter, resulting in a reconfigurable centre frequency of the device.

\section{Switchable Coupler}

The dual-band coupler device presented here is comparable to varactor tuned devices [5] in terms of fabrication complexity. However varactor based designs often require biasing lines and short circuit vias.

The switches used in the design of a branch-line coupler are diced from high resistivity silicon wafer $(\rho>6000 \Omega \mathrm{cm})$. Silicon changes from an insulator state to a near conducting state when illuminated by light. Silicon used is n-type doped with Phosphorus to increase static conductivity. The ideal light for this process is in the near infrared range. If we assume that the carrier mobilities do not change for low dopant densities, the free electron and hole densities for a static conductivity of $16.67 \times 10^{-3} \mathrm{~S} / \mathrm{m}$ can be found as $e_{0}=7.7 \times 10^{11} / \mathrm{cm}^{3}$ and $h_{0}=2.9 \times 10^{8} / \mathrm{cm}^{3}$, as shown in [1]. When illuminated with light, an equal number of excess electrons and holes are generated in pairs, adding to the initial free carrier densities. The excess free carrier density $(e+h)$ can be related to the relative complex permittivity of the semiconductor [11].

$$
\varepsilon_{r}=\varepsilon_{L}-\left(\left(\frac{\omega_{p e_{0}}^{2}}{\omega^{2}+v^{2}}+\frac{\omega_{p e}^{2}}{\omega^{2}+v^{2}}+\frac{\omega_{p h_{0}}^{2}}{\omega^{2}+v^{2}}+\frac{\omega_{p h}^{2}}{\omega^{2}+v^{2}}\right)\left(1+j \frac{v}{\omega}\right)\right)
$$


where $\omega_{p e_{0}}^{2}=\frac{e_{0} q^{2}}{\varepsilon_{0} m^{*}}, \omega_{p e}^{2}=\frac{e q^{2}}{\varepsilon_{0} m^{*}}, \omega_{p h_{0}}^{2}=\frac{h_{0} q^{2}}{\varepsilon_{0} m^{*}}, \omega_{p h}^{2}=\frac{h q^{2}}{\varepsilon_{0} m^{*}}, q$ is the electron charge, $\varepsilon_{r}$ is complex relative permittivity of the electron-hole plasma $\left(\varepsilon_{r}=\varepsilon^{\prime}-j \varepsilon^{\prime \prime}\right), \varepsilon_{0}$ is permittivity of vacuum, $\varepsilon_{L}$ is relative permittivity of the semiconductor without the plasma, $m^{*}$ is the effective mass of the charge carrier, $v$ is the charge carrier collision frequency. The equivalent conductivity of silicon $\left(\sigma_{e}\right)$ is made of static $\left(\sigma_{s}\right)$ and alternating parts $\left(\sigma_{a}\right)$, which can be shown by inserting (1) into Maxwell-Ampere law (2)-(4):

$$
\begin{gathered}
\nabla \times \overline{\mathbf{H}}=\sigma \overline{\mathbf{E}}+j \omega\left(\varepsilon^{\prime}-j \varepsilon^{\prime \prime}\right) \overline{\mathbf{E}} \\
\nabla \times \overline{\mathbf{H}}=\left(\sigma+\omega \varepsilon^{\prime \prime}\right) \overline{\mathbf{E}}+j \omega \varepsilon \overline{\mathbf{E}} \\
\nabla \times \overline{\mathbf{H}}=\sigma_{e} \overline{\mathbf{E}}+j \omega \varepsilon^{\overline{\mathbf{E}}}
\end{gathered}
$$

where $\sigma_{e}=\sigma_{s}+\sigma_{a}=\sigma_{s}+\omega \varepsilon^{\prime \prime}, \sigma_{a}=\omega \varepsilon^{\prime \prime}$.

Change in static, alternating and equivalent conductivity with increase of total free carrier density $\left(e_{0}+h_{0}+e+h\right)$ is shown in Figure 1.

A way of modelling the switch is by matching the experimental results for the optical switch and simulation results for the equivalent circuit of the switch. The results for different states of the switch were obtained using Agilent Advanced Design System. The lumped element values from Figure 2 are tuned in order to match measured S-parameters under various illumination powers, from 0 to $200 \mathrm{~mW}$. The gap is represented by three capacitors $(\mathrm{C} 1, \mathrm{C} 2, \mathrm{C} 4)$ and two additional components (R3, C3) to account for the photoconducting effect of silicon. Resistors (R1, R2) and inductors (L1, L2) are added to account for losses. By analysing a number of S-parameter graphs it was shown that with increasing optical power, the gap capacitance values (C2 and C3) increase, while the gap resistance values ( $\mathrm{R} 1, \mathrm{R} 2$ and $\mathrm{R} 3$ ) decrease, indicating a capacitive nature of the switch. The values of these elements are shown in Table 1.

An example of the switch in a microstrip transmission line is shown in Figure 3 . The $1 \mathrm{~mm} \times 2 \mathrm{~mm}$ x $0.3 \mathrm{~mm}$ silicon dice was placed over a $0.5-\mathrm{mm}$ gap. A transmission line was printed on a $1.57-\mathrm{mm}$ 
International Journal of RF \& Microwave CAE

Rogers RT/Duroid 5880 substrate with a dielectric constant of 2.2. The same substrate was used for branch-line coupler design. The silicon switch was held in place using a RS silver loaded epoxy hardener. The measured S-parameters for the switched line in OFF $(0 \mathrm{~mW})$ and ON state $(200 \mathrm{~mW})$ are given in Figure 4. The architecture of a dual-band coupler is shown in Figure 5. The characteristic impedances and electrical lengths, widths and lengths of the lines corresponding to the ones shown in Figure 5 are presented in Table 2. When silicon switches are in OFF state, there is a considerable degree of electrical isolation between TLS1 and TLS2. Consequently, very little energy transfer occurs across the gap. When switches are ON, they operate in pseudo-metallic state, an electrical connection is formed between TLS1 and TLS2.

A $980 \mathrm{~nm}$ laser operating at $200 \mathrm{~mW}$ is coupled with fiber optic cables and angled over silicon wafers using plastic clamps. When laser is off, all switches are off. When laser is on, operating at $200 \mathrm{~mW}$, the silicon conducts and the gaps are bridged, increasing the lengths of stubs and reducing the resonant frequency. Although the refractive index of silicon is varied by applying laser power to the material, even in the worst-case contribution of the thermo-optic effect, this change is very small and the coupler performance is not temperature sensitive.

\section{Frequency Switchable S-band Power Amplifier}

The frequency characteristics of an amplifier depend mainly on its input matching circuit. The idea presented here was to use reconfigurable input matching circuit and the output matching circuit was designed with fixed-value elements to cover the whole frequency tuning range without significant implications to efficiency and linearity. The wider tuning range would be possible if the additional input matching networks with the additional switches were inserted [14], but the complexity and size of the circuit would be increased.

In the simulations the accurate large signal model of the CREE CGH35015F GaN HEMT device was used. The active device was initially recommended for $3.5 \mathrm{GHz}$ OFDM WiMAX applications (12 dB Small Signal Gain, $26 \%$ Efficiency at 2 W Average Power). A 0.508-mm-thick Rogers 
International Journal of RF \& Microwave CAE

Duroid 5880 substrate with dielectric constant of 2.2 was used for the matching networks. A model of the device was characterised, then the biasing circuit was added, load-pull simulations were performed. Finally, the input and output matching network design procedure was applied. The schematic of the reconfigurable power amplifier is shown in Figure 6. The dimensions of the lines are shown in Table 3. The dimensions of the upper (transmission line) and lower part of the tunable stub are given as Line and Stub 2 respectively. The gap is $0.25 \mathrm{~mm}$ wide.

\section{Results}

The simulations were performed using Agilent Advanced Design System 2008 and Agilent Momentum, the 2.5D electromagnetic simulation engine within the ADS package, that employs the Method of Moments technique. The simulated scattering parameter input and output port responses (magnitude response) for two states of the switch $(0 \mathrm{~mW}$ and $200 \mathrm{~mW})$ are shown in Figure 7 and 8 respectively.

The infrared $980 \pm 0.5 \mathrm{~nm}$ laser is used in the experiment. An electronic control system alters the amount of optical power produced by the laser. The scattering parameter measurements were obtained using and Anritsu 37397D vector network analyzer. The measured S-parameter input and output port responses are shown in Figures 9 and 10. Good reflection is shown in both frequency bands (better than $-15 \mathrm{~dB}$ ). The coupling is close to $-3 \mathrm{~dB}$ in both bands. The simulated and measured results are in good agreement. The frequency shift of $230 \mathrm{MHz}$ and $160 \mathrm{MHz}$ are demonstrated in lower $(900 \mathrm{MHz})$ and upper $(1800 \mathrm{MHz})$ frequency bands, respectively. The percentage frequency shift is $35 \%$ and $10 \%$ in lower and upper bands, respectively.

Power Amplifier simulations were performed in Agilent ADS 2008. Figure 11 shows the simulated frequency response for the $2.5-\mathrm{GHz}$ mode (a) and the $3.5-\mathrm{GHz}$ mode (b), respectively. The device 
International Journal of RF \& Microwave CAE

was biased for the operation in class $-\mathrm{AB}\left(\mathrm{V}_{\mathrm{DD}}=28 \mathrm{~V}\right)$. The gain of $15 \mathrm{~dB}$ was reached in both modes. Figure 12 shows power added efficiency (PAE) for various input powers for both modes ( $0 \mathrm{~mW}$ and $200 \mathrm{~mW})$. The device was biased under the conditions described above. The maximum PAE is $33 \%$. The power amplifier achieves almost the same level of PAE as the one of single band power amplifier. After testing the amplifier under various input power levels it was shown that intermodulation distortion levels are almost the same as the standard single band amplifier. The simulated C/IM3 is shown in Figure 13.

\section{Conclusion}

This paper has proposed frequency switchable RF circuits using photoconducting switches: a frequency switchable dual-band branch-line coupler and a frequency switchable S-band power amplifier. The silicon gap-loaded switch properties were changed from insulator state to near conducting state under illumination and resulted in the change of the effective length of the transmission line. The frequency switchable power amplifier with simple circuit topology has shown considerably good efficiency and linearity, although even higher linearity and power levels could be obtained by designing more complex tunable matching networks at both input and output. An optically switchable dual-band branch-line coupler has been demonstrated, both through simulation and measurements. The frequency shift of $35 \%$ and $10 \%$ has been achieved from all switches off to all switches on in lower and upper frequency bands, respectively. The branch line coupler's performance has shown near $-3 \mathrm{~dB}$ insertion loss, good return and isolation loss better than $-15 \mathrm{~dB}$ and near 90 degrees phase difference between coupled and through ports, in both bands. The advantages of these new frequency switchable RF circuits are high-speed switching, electromagnetic transparency (no interference), thermal and electrical isolation between the device and the control circuit, and no need for short circuit vias and biasing lines. 
International Journal of RF \& Microwave CAE

\section{References}

[1] C. J. Panagamuwa, A. Chauraya, and J. C. Vardaxoglou, "Frequency and beam reconfigurable antenna using photoconducting switches," Antennas and Propagation, IEEE Transactions on, vol. 54, pp. 449-454, 2006.

[2] A. Chauraya, J. Kelly, R. D. Seager, and J. C. Vardaxoglou, "Frequency switchable microstrip filter for microwave frequencies," presented at European Microwave Conference, 20052005.

[3] G. Zouganelis and D. Budimir, "Silicon gap-loaded microstrip slit-tetragonal resonator under IR-irradiation," in Microwave and Optical Technology Letters. vol. 49, 2007, pp. 699-702.

[4] M. El Khaldi, F. Podevin, and A. Vilcot, "Optically controlled phase-shifter based on gaps on microstrip line,".

[5] E. E. Djoumessi, E. Marsan, C. Caloz, M. Chaker, and K. Wu, "Varactor-Tuned Dual-Band Quadrature Hybrid Coupler," Microwave and Wireless Components Letters, IEEE, vol. 16, pp. 603-605, 2006.

[6] D. H. Auston, "Picosend optoelectronic switching and gating in silicon," Appl. Phys. Lett., vol. 26, pp.101-103, Feb 1975.

[7] I. L. Anderson and T. Sverre, "Phase and Amplitude Characteristics of InP:Fe Modified Interdigitated Gap Photoconductive Microwave Switches," IEEE Transactions on Microwave Theory and Techniques, Vol. 37, No. 4, April 1989. 
International Journal of RF \& Microwave CAE

[8] Y. Horii and M. Tsutsumi, "Scattering Parameters of Interdigital Microstrip Gap Under Laser Spot Illumination,” IEEE MTT-S Digest, pp 1635 - 1638, 1997.

[9] S. S. Gevorgian, "Design Consideration for an Optically Excited Semiconductor Microstrip Gap at Microwave Frequencies.” IEE Proc-J., Vol. 139, No. 2., pp 153-157, April 1992.

[10] E. Yablonovitch, "Inhibited spontaneous emission in solid-state physics and electronics", Phys. Rev. Lett. 58: pp. 2059-2061, 1987.

[11] C. H. Lee, P. S. Mak, and A. P. DeFonzo, "Optical control of millimeterwave propagation in dielectricwaveguides,” IEEE J. Quantum Electron., vol. 16, no. 3, pp. 277-288, 1980.

[12] Y. L. R. Lee, A. Chauraya, D. S. Lockyer and J. C. Vardaxoglou, "Dipole and tripole metallodielectric photonic (MPBG) structures for microwave filter and antenna applications,” IEE Proc.-Optoelectron, Vol. 147, No. 6, Dec 2000

[13] S. Collardey, G. Poilasne, A. C. Tarot, P. Pouliguen, C. Terret and K. Mahdjoudi, "Metallic photonic bandgap propagation mode characterization," Microwave and Optical Technology Letters, Vol. 28, No. 6, pp. 434-440, March 2001.

[14] F. Atsushi, O. Hiroshi, and N. Shoichi, "A Novel Compact Reconfigurable Quad-band Power Amplifier Employing RF-MEMS Switches," presented at Microwave Conference, 2006. 36th European, 2006. 
International Journal of RF \& Microwave CAE

[15] W. C. E. Neo, Y. Lin, X. D. Liu, L. C. N. De Vreede, L. E. Larson, M. Spirito, M. J. Pelk, K. Buisman, A. Akhnoukh, A. De Graauw, and L. K. Nanver, "Adaptive Multi-Band MultiMode Power Amplifier Using Integrated Varactor-Based Tunable Matching Networks," SolidState Circuits, IEEE Journal of, vol. 41, pp. 2166-2176, 2006.

[16] H. Uchida, K. Ogura, Y. Konishi, and S. Makino, "A frequency-tunable amplifier with a simple tunable admittance inverter," presented at Microwave Conference, 2005 European, 2005. 
TABLE I

R, L, C Values As A Function of Laser Power

\begin{tabular}{|c|c|c|c|}
\hline \multirow{3}{*}{ OFF $(0 \mathrm{~mW})$} & $\mathrm{L} 1=1 \mathrm{nH}$ & $\mathrm{L} 2=1 \mathrm{nH}$ & $\mathrm{C} 4=1 \mathrm{pF}$ \\
\cline { 2 - 4 } & $\mathrm{R} 1=800 \Omega$ & $\mathrm{R} 2=800 \Omega$ & $\mathrm{R} 3=800 \Omega$ \\
\cline { 2 - 4 } & $\mathrm{C} 1=1 \mathrm{pF}$ & $\mathrm{C} 2=1 \mathrm{pF}$ & $\mathrm{C} 3=1 \mathrm{pF}$ \\
\hline \multirow{3}{*}{$\mathrm{ON}(200 \mathrm{~mW})$} & $\mathrm{L} 1=41 \mathrm{nH}$ & $\mathrm{L} 2=41 \mathrm{nH}$ & $\mathrm{C} 4=23 \mathrm{pF}$ \\
\cline { 2 - 4 } & $\mathrm{R} 1=50 \Omega$ & $\mathrm{R} 2=50 \Omega$ & $\mathrm{R} 3=50 \Omega$ \\
\cline { 2 - 4 } & $\mathrm{C} 1=23 \mathrm{pF}$ & $\mathrm{C} 2=23 \mathrm{pF}$ & $\mathrm{C} 3=23 \mathrm{pF}$ \\
\hline
\end{tabular}

TABLE II

ChaRACTERISTIC ImPEDANCES AND ELECTRICAL LENGTHS OF THE TRANSMISSION LINES

\begin{tabular}{|l|c|c|c|c|}
\hline & $\begin{array}{l}\text { Impedance } \\
(\mathbf{\Omega})\end{array}$ & $\begin{array}{l}\text { Electrical } \\
\text { Length } \\
\text { (degrees) }\end{array}$ & $\begin{array}{l}\text { Width } \\
(\mathbf{m m})\end{array}$ & $\begin{array}{l}\text { Length } \\
(\mathbf{m m})\end{array}$ \\
\hline TL1 & 42.7 & 90 & 1.95 & 37.45 \\
\hline TL2 & 60.4 & 90 & 1.15 & 38.06 \\
\hline TLS1 & 54.4 & 75.6 & 1.36 & 31.50 \\
\hline TLS2 & 54.4 & 27 & 1.36 & 11.36 \\
\hline
\end{tabular}

TABLE III

Dimensions of THE INPUT MATCHING NeTWORK TRANSMISSION LINES

\begin{tabular}{|c|c|c|c|}
\hline \multicolumn{2}{|c|}{$\begin{array}{c}\text { Transmission } \\
\text { line }\end{array}$} & $\begin{array}{c}\text { Width } \\
(\mathrm{mm})\end{array}$ & $\begin{array}{c}\text { Length } \\
(\mathrm{mm})\end{array}$ \\
\hline \multicolumn{2}{|c|}{ Stub 1 } & 2.17 & 9.58 \\
\hline \multicolumn{2}{|c|}{ Stub 2 } & 8.02 & 7.63 \\
\hline \multicolumn{2}{|c|}{ Line } & 8.02 & 6.45 \\
\hline \multirow{2}{*}{ Main } & $d_{1}$ & 2.95 & 4.68 \\
\cline { 2 - 4 } Input & $d_{2}$ & 2.95 & 29.41 \\
\cline { 2 - 4 } & $d_{3}$ & 2.95 & 34.75 \\
\hline
\end{tabular}




\section{List of figure captions}

Figure 1: Change in conductivity with the increase of total free carrier density.

Figure 2: Equivalent circuit of the switch.

Figure 3: Example of a switch in a microstrip transmission line.

Figure 4: Measured magnitude response of the switch in OFF (a) and ON (b) states.

Figure 5: Architecture of a dual-band switchable branch-line coupler.

Figure 6: Schematic of the reconfigurable power amplifier circuit (biasing circuit is omitted).

Figure 7: Simulated S-parameters of the frequency switchable branch-line coupler in OFF state (0 $\mathrm{mW})$.

Figure 8: Simulated S-parameters of the frequency switchable branch-line coupler in ON state (200 $\mathrm{mW})$.

Figure 9: Measured S-parameters of the frequency switchable branch-line coupler in OFF state (0 $\mathrm{mW})$.

Figure 10: Measured S-parameters of the frequency switchable branch-line coupler in ON state $(200 \mathrm{~mW})$.

Figure 11: S-parameters versus frequency for two positions of the switch $(0 \mathrm{~mW}$ and $200 \mathrm{~mW}$, for (a) and (b), respectively).

Figure 12: Power Added Efficiency versus RF Power for both positions of the switch (0 $\mathrm{mW}$ and $200 \mathrm{~mW}$, for Positions 1 and 2, respectively).

Figure 13. C/IM3 versus Output Power for both positions of the switch $(0 \mathrm{~mW}$ and $200 \mathrm{~mW}$ for Positions 1 and 2, respectively). 
International Journal of RF \& Microwave CAE

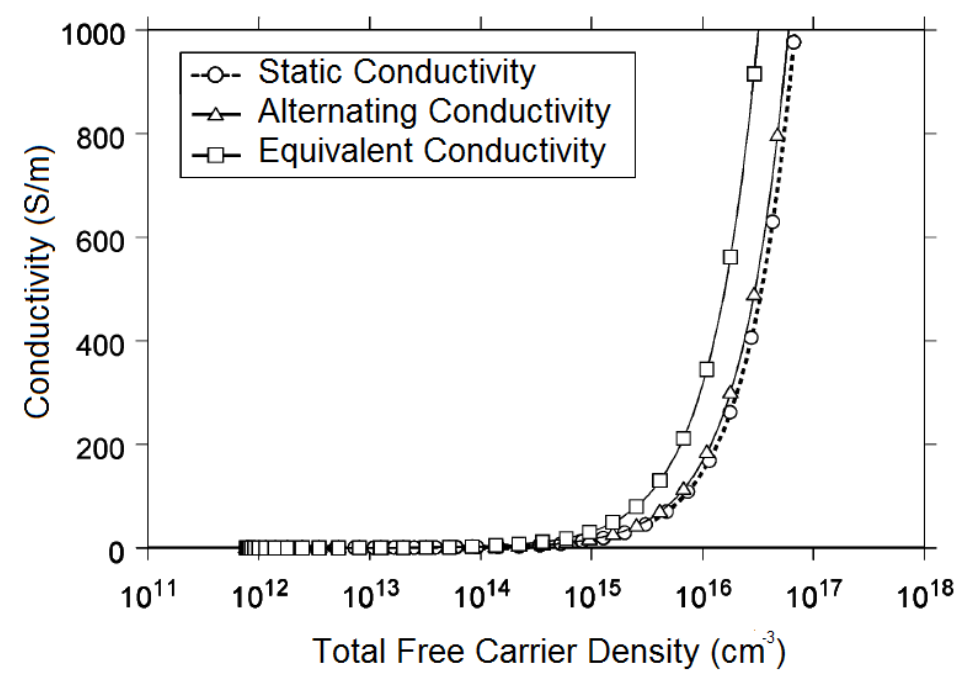

Figure 1. Change in conductivity with the increase of total free carrier density.

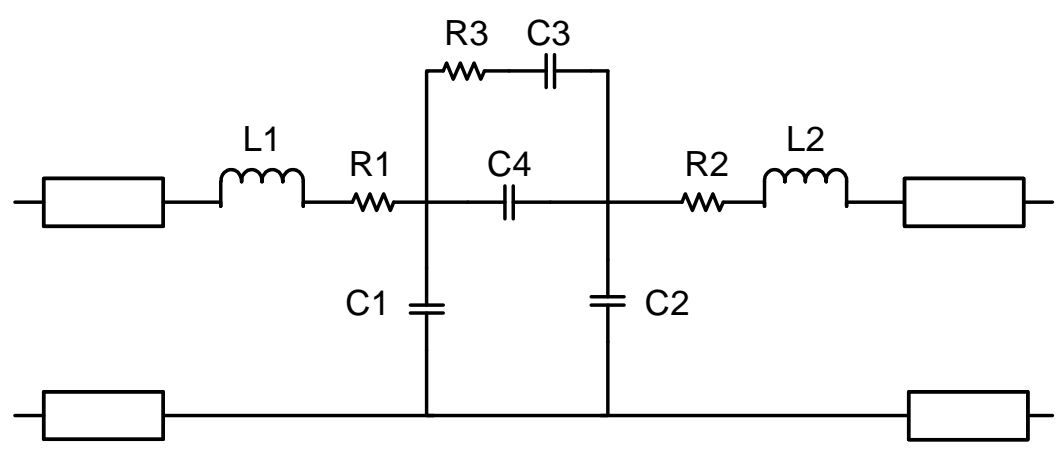

Figure 2. Equivalent circuit of the switch.

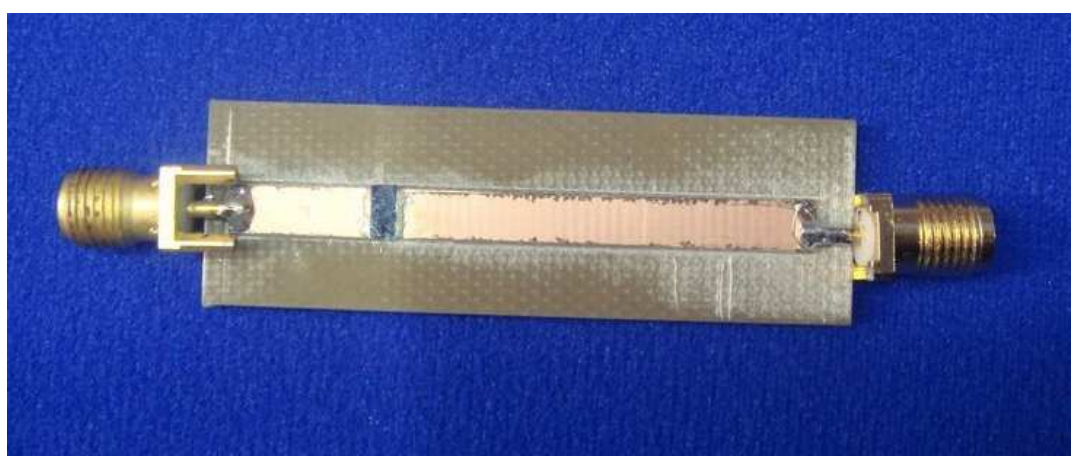

Figure 3. Example of a switch in a microstrip transmission line. 
International Journal of RF \& Microwave CAE

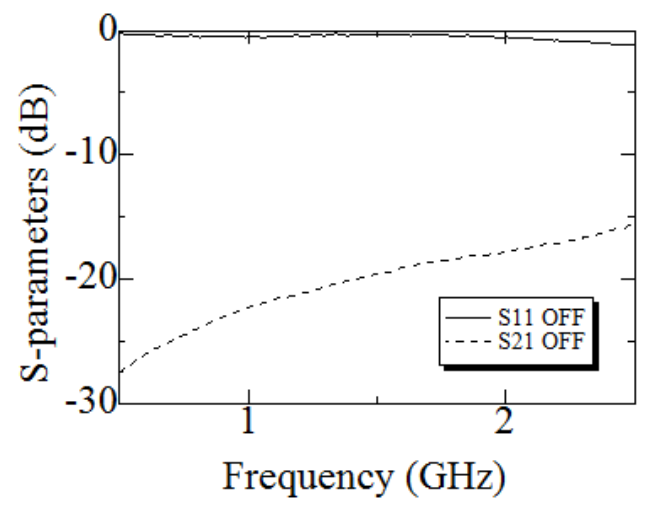

a)

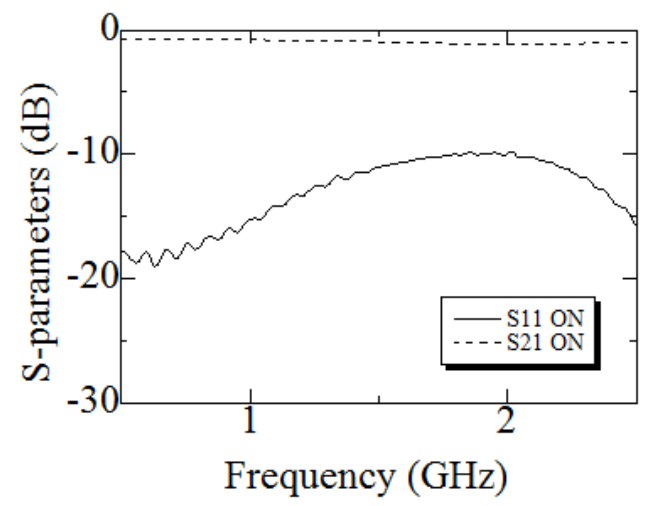

b)

Figure 4. Measured magnitude response of the switch in OFF (a) and ON (b) states.

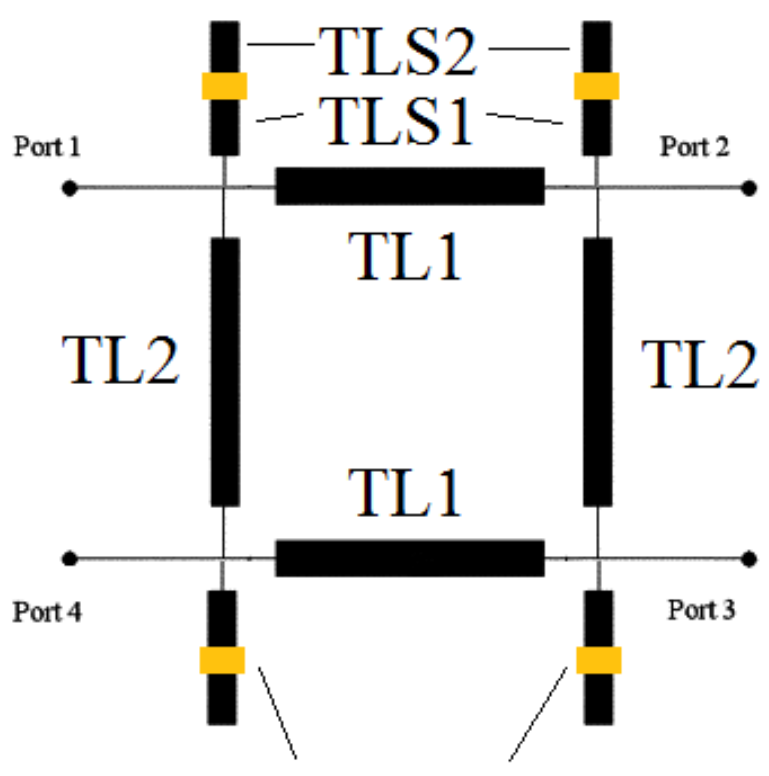

Silicon Switch

Figure 5. Architecture of a dual-band switchable branch-line coupler. 


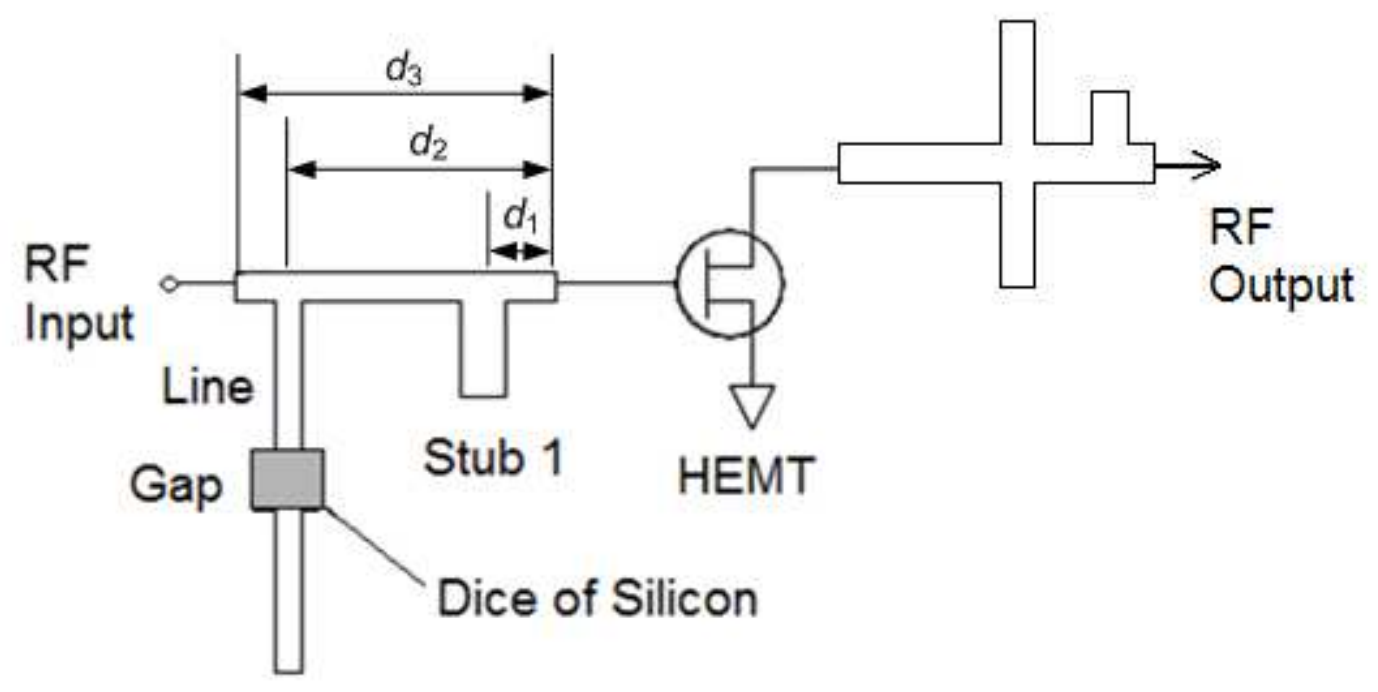

Stub 2

Figure 6. Schematic of the reconfigurable power amplifier circuit (biasing circuit is omitted).

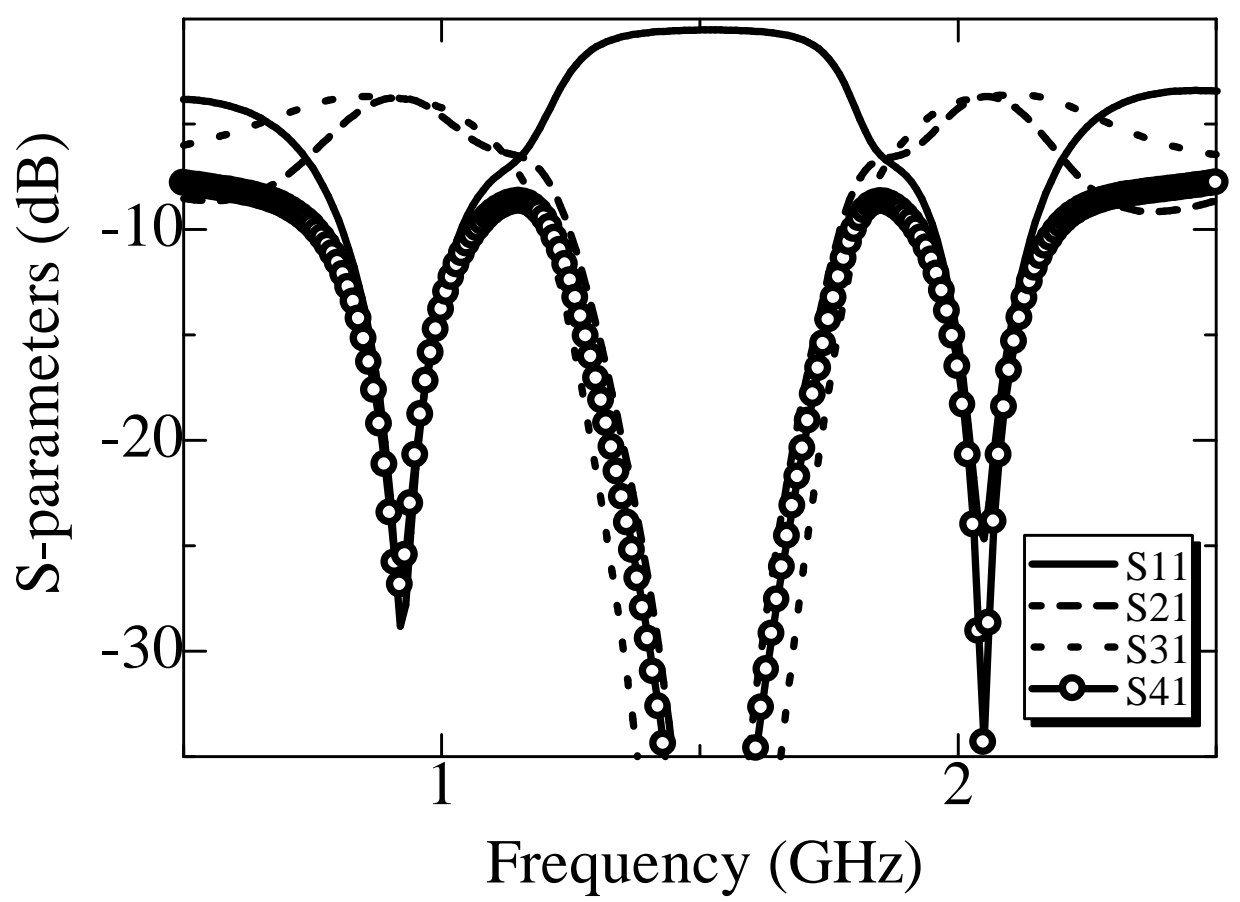

Figure 7. Simulated S-parameters of the frequency switchable branch-line coupler in OFF state $(0 \mathrm{~mW})$. 


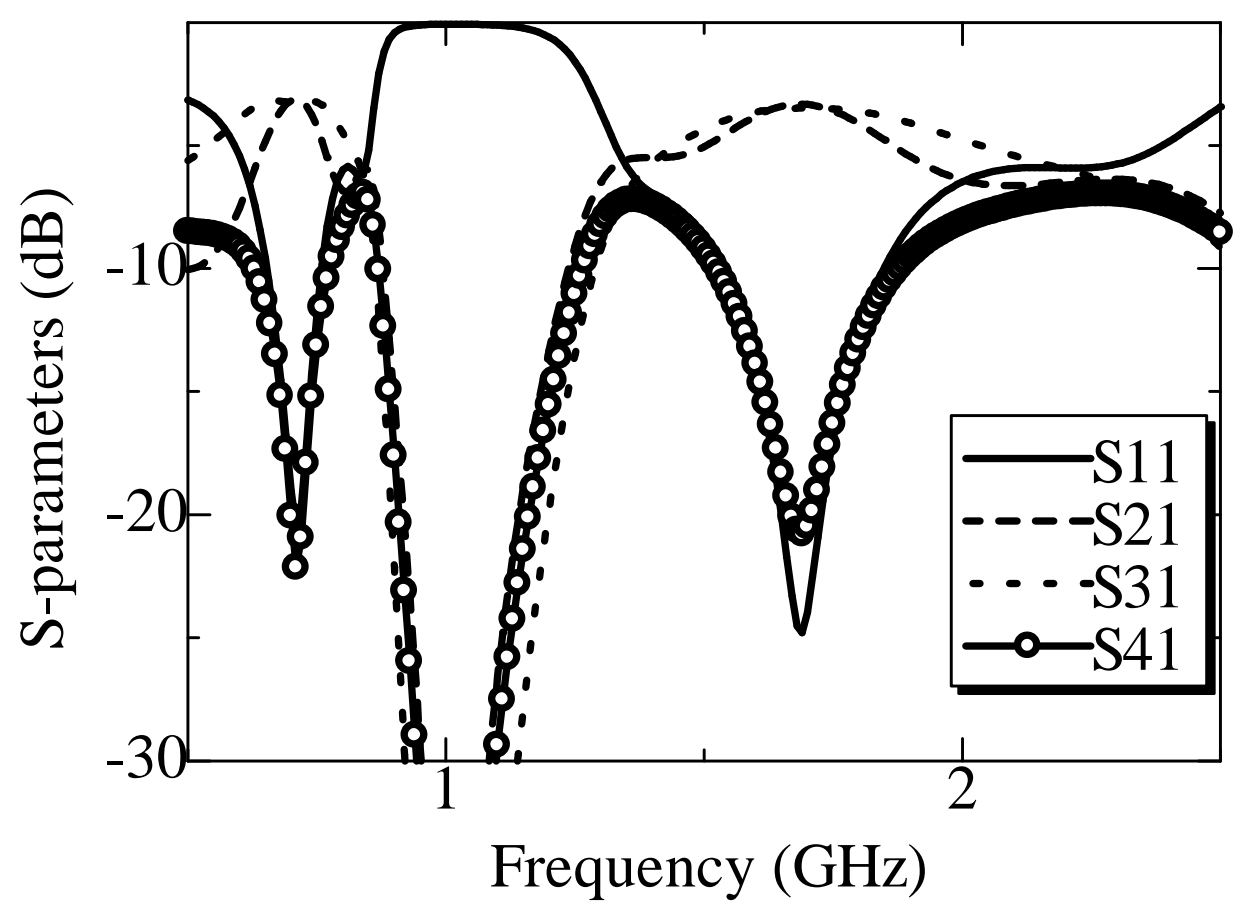

Figure 8. Simulated S-parameters of the frequency switchable branch-line coupler in ON state (200 $\mathrm{mW})$.

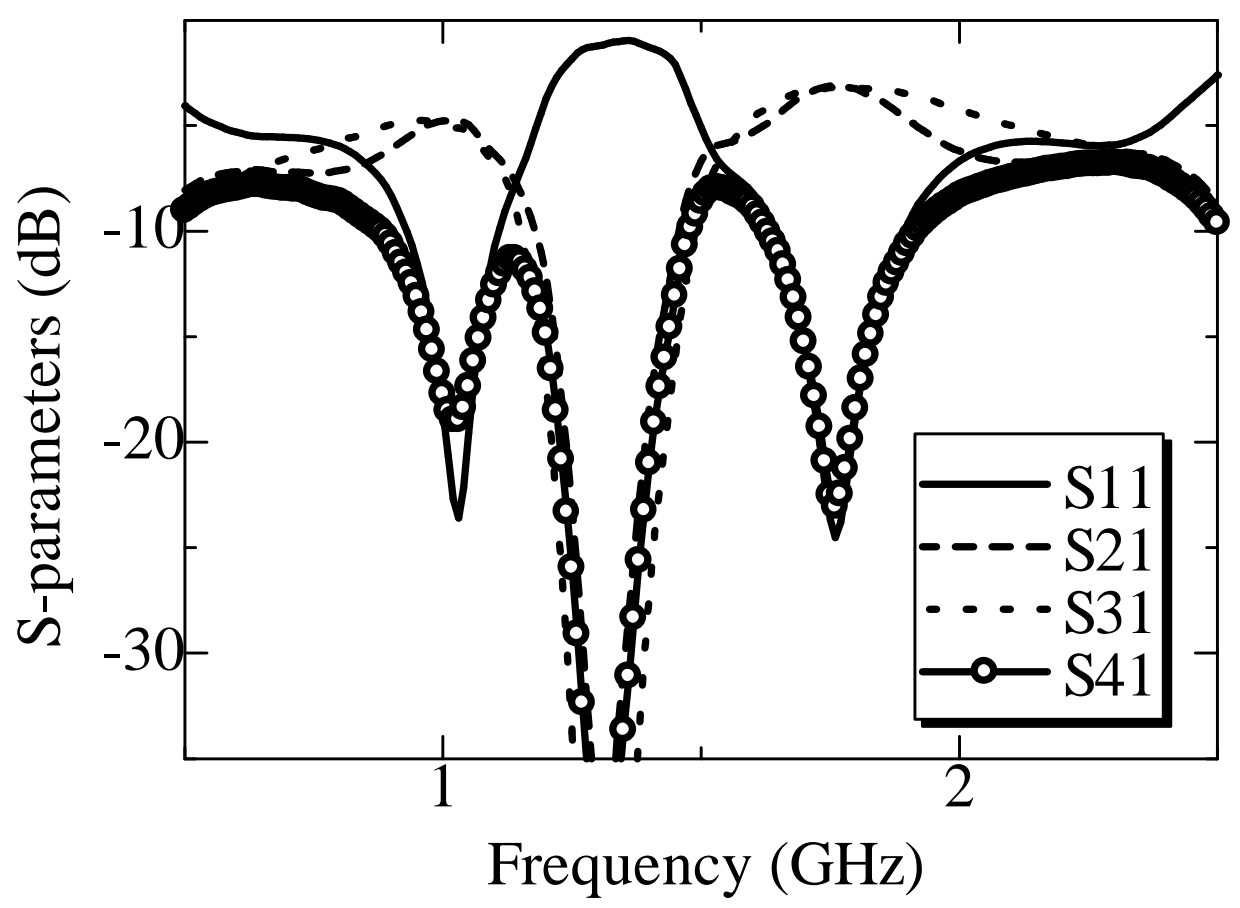

Figure 9. Measured S-parameters of the frequency switchable branch-line coupler in OFF state (0 $\mathrm{mW})$. 


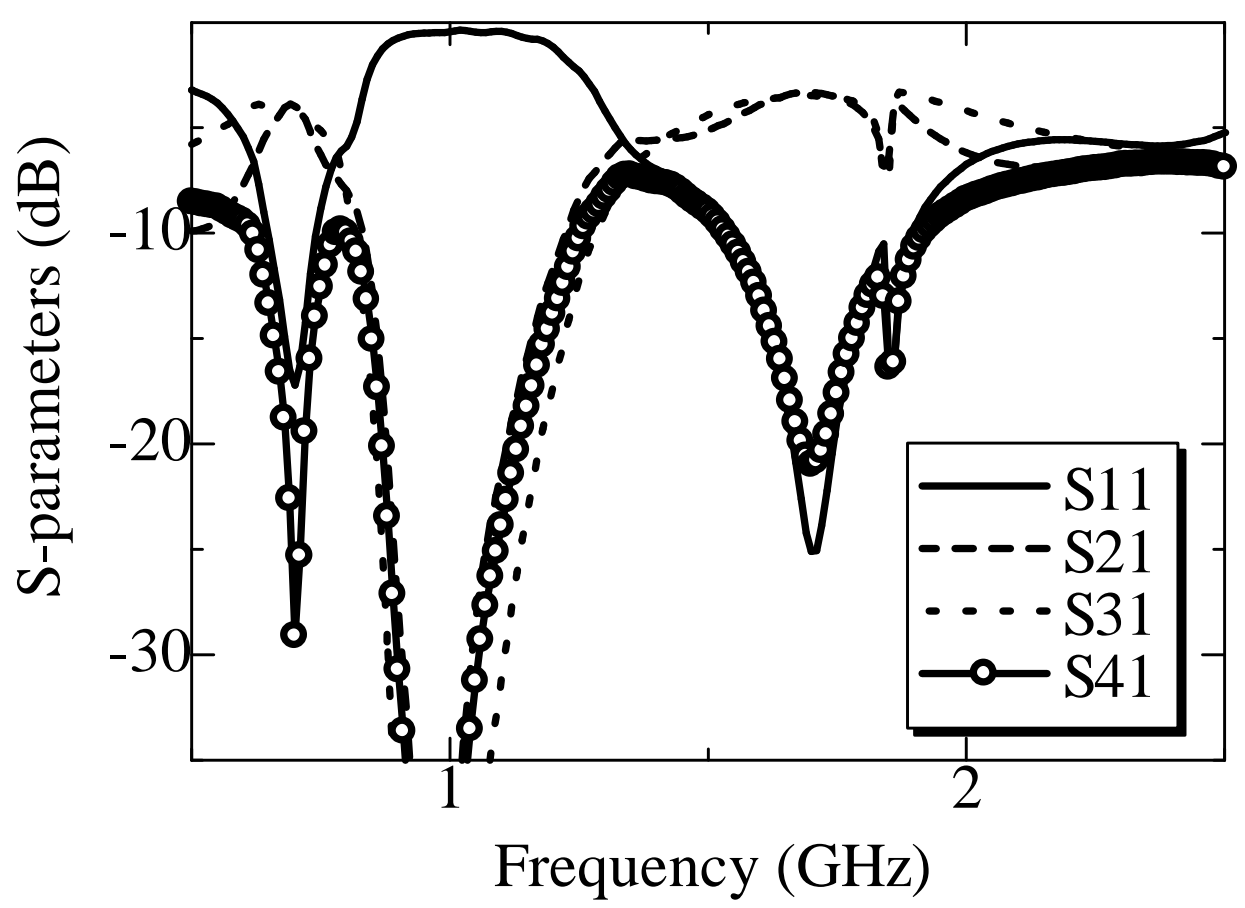

Figure 10. Measured S-parameters of the frequency switchable branch-line coupler in ON state $(200 \mathrm{~mW})$. 


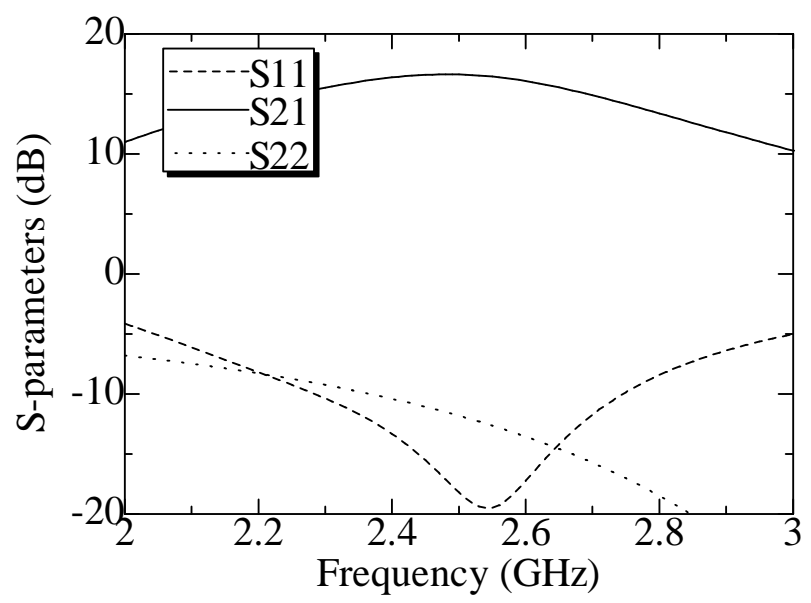

(a)

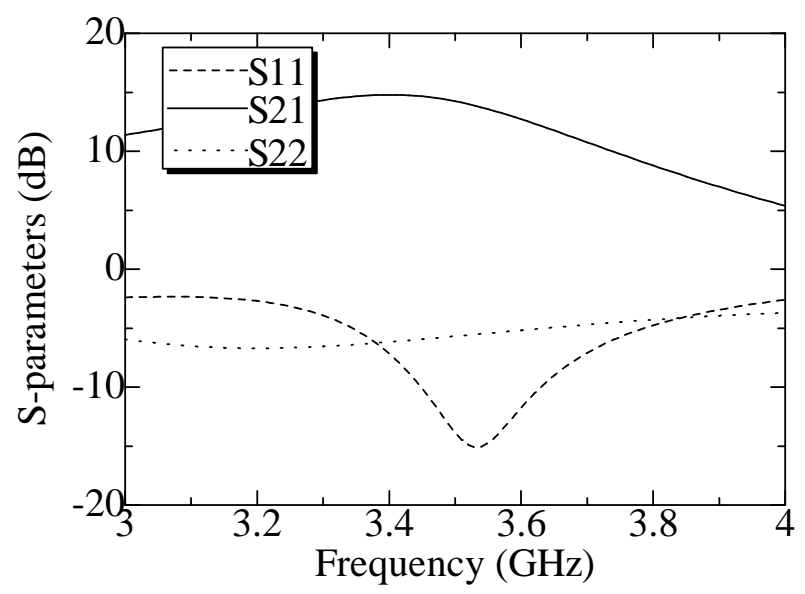

(b)

Figure 11. S-parameters versus frequency for two positions of the switch $(0 \mathrm{~mW}$ and $200 \mathrm{~mW}$, for (a) and (b), respectively). 
International Journal of RF \& Microwave CAE

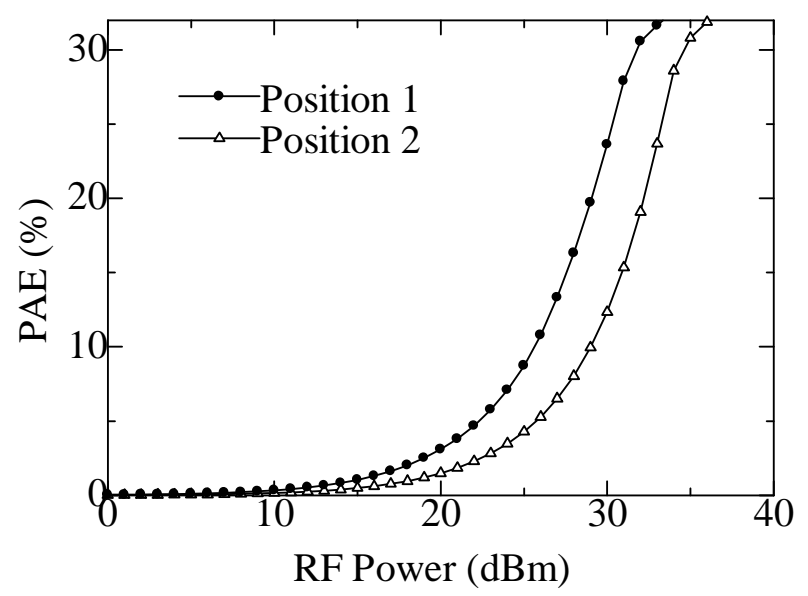

Figure 12. Power Added Efficiency versus RF Power for both positions of the switch $(0 \mathrm{~mW}$ and $200 \mathrm{~mW}$, for Positions 1 and 2, respectively).

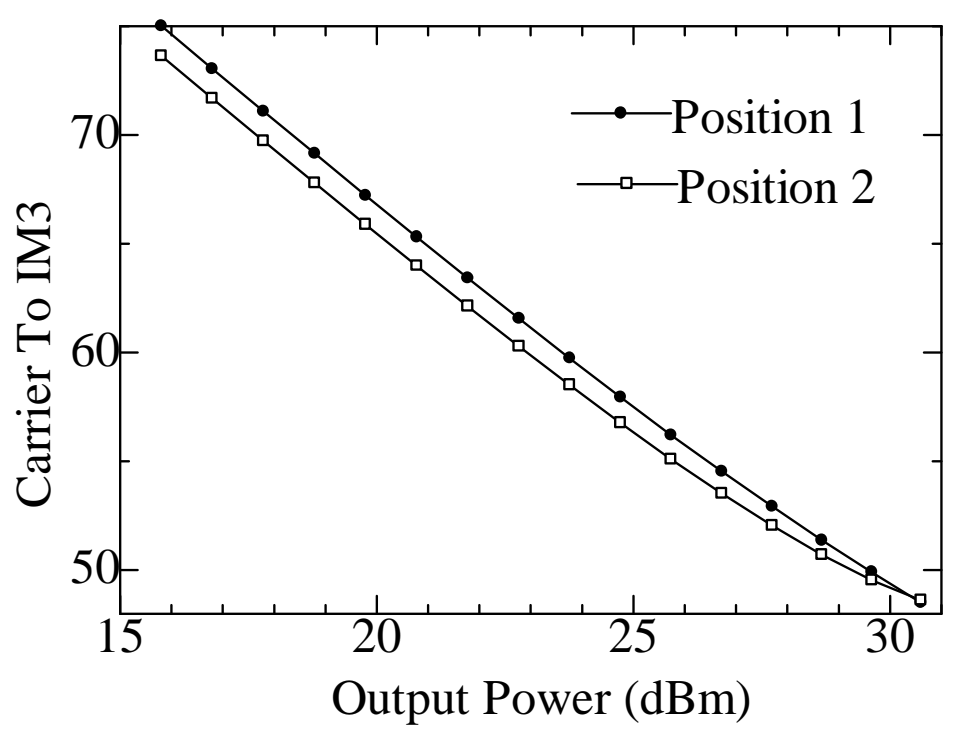

Figure 13. C/IM3 versus Output Power for both positions of the switch $(0 \mathrm{~mW}$ and $200 \mathrm{~mW})$. 